7. Lagrange, Felix.-De la méthode fistulisante dans la cure du Glaucome Chronique. Valeur comparée des divers procédés opératoires. Arch. d'Ophtal., Février, 1914.

Des opérations décompressives dans le traitement du Glaucome Chronique. Arch. d'Ophtal., Novembre, 1920.

8. Lagrange, Henry - Petits détails de technique concernant la Sclerectomie limbique faite au couteau. Ann. d'Ocul., Tome CLXIII, p.' 695, Septembre, 1926.

9. Joseph, Etienne.-Resultats éloignés des opérations antiglaucomateuses. Thèse de Paris, 1935.

10. Lagrange, Felix.-Du Glaucome et de 1'Hypotonie. G. Doin et Cie Ed., Paris, 1922.

\title{
THE USE OF RADON IN THE TREATMENT OF METASTATIC CARCINOMA OF THE CHOROID
}

BY

\section{P. JAMESON Evans \\ BIRM INGHA M}

THE case described is unusual in the development of metastatic carcinoma, secondary to that of the breast, in both eyes, in the one two months before the other. The first eye was excised, the fellow eye at that time being normal, and the second treated by the application of radon seeds.

N.D., aged 41 years, female, first attended the Birmingham and Midland Eye Hospital complaining of a foreign body in the left eye on December 16, 1935, when vision was: R. 6/6, L. 6/9. (i) There was some conjunctivitis of the left eye but no foreign body was found. On January 6,1936 , the patient complained of defective left vision of about ten days duration, and was found to have (LV) less than 6/60. A pale exudate was seen in the fundus of the left eye situated to the nasal side of the disc, extending from the disc outwards. This continued to increase slowly in size

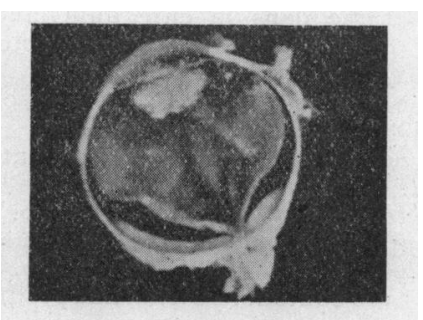

FiG. 1

Choroid of Left Eye. 
for a fortnight. It was not till then that the history was elicited of the removal of the left breast for carcinoma in 1932. The condition in the left fundus was then considered to be probably a metastatic growth and, accordingly, the eye was excised on January 27 (Fig. 1).

The pathological report on the specimen runs "secondary adeno-carcinoma." Vision in the right eye was at this time $6 / 6$ and the fundus appeared normal.

On March 9, 1936, the patient was seen again complaining of mistiness of vision in the right eye. Vision was $6 / 36$, and examination showed a large, pale, flat detachment spreading from the

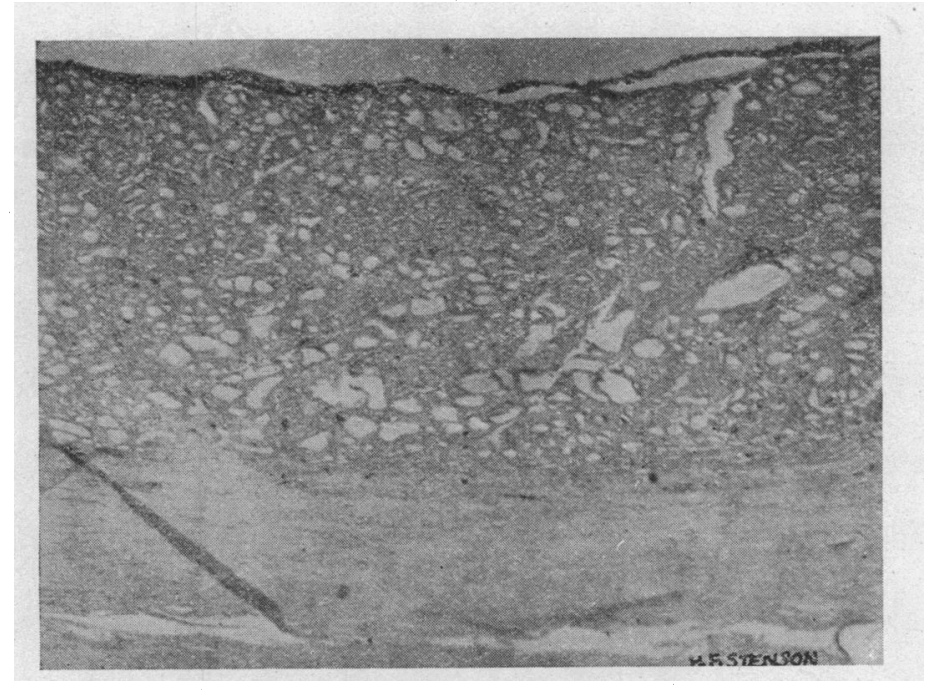

FIG. 2.

Microscopic section of growth in left eye

optic disc downwards and outwards, below the line of the inferior temporal vessels of similar appearance to that seen in the left eye prior to excision. The patient was transferred to Queen's Hospital, Birmingham. Upon admission on March 10 vision in the right eye was 6/60 or less, and it was decided to give an application of radium emanation.

On March 23, 1936, the following operation was performed on the right eye.

The eye was prepared as for a diathermy operation for detached retina. The conjunctiva was cut in a semicircle below from 3 o'clock to 9 o'clock and resected widely. The inferior rectus muscle was secured and cut, the posterior end being retained on 
a catgut suture. The lower half of the sclera was then exposed. Four radon seeds, having an initial activity of 1.72 millicuries each were stitched to the sclera; two were placed twelve millimetres back from the limbus and ten millimetres apart, on each side of the inferior rectus, and two fifteen millimetres back and eight millimetres apart. A second thread for the purpose of withdrawal was attached to each seed and brought out through the

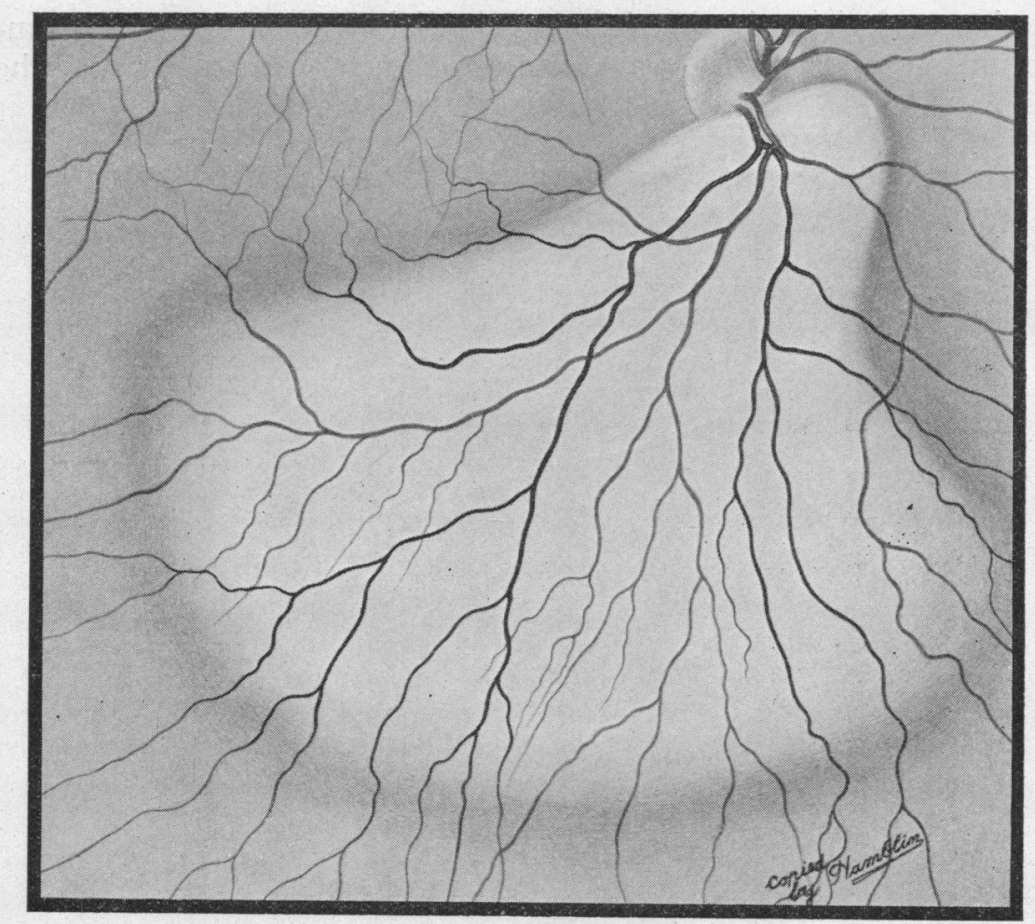

FIG. 3.

Drawing of right fundus before operation. March 20, 1936

conjunctival wound, while the scleral sutures were brought forward through the lower lid and tied off in pairs, inner and outer, over thin rubber tubing. The inferior rectus was then re-sutured in its previous position, and the conjunctival wound closed. At the end of a week the radon seeds were removed without re-opening the wound. Healing was uneventful.

On April 17 vision was slightly improved but no change could be seen in the fundus picture. On April 24 right vision was 6/12 full. On May 8 there were seen four areas of degeneration in 
the growth, like gaps in a mist, corresponding to the positions occupied by the four radon seeds.

On May 29 vision with $\frac{-0.50}{0.50}$ was $6 / 6$ full.

The eye movements were full and there was no drag on the conjunctival scar. The retina was entirely flat, the yellow growth having disappeared, but there was widespread choroidal reaction with pigmentation, which appeared to be spreading in all directions and involved the macular area. This change in the choroid continued to spread, finally reaching the line of the superior temporal retinal vessels above, and extending below out of view towards the ora serrata, while laterally the extension was approximately from 4 o'clock of the cornea to 8 o'clock. On June 4 the right field for $\frac{10}{2}$ white at $1 / 3$ metre was perfectly full and vision was $6 / 5$ part with glasses. The fundus picture was unchanged, the area affected showing much stippling of pigmentary change in the

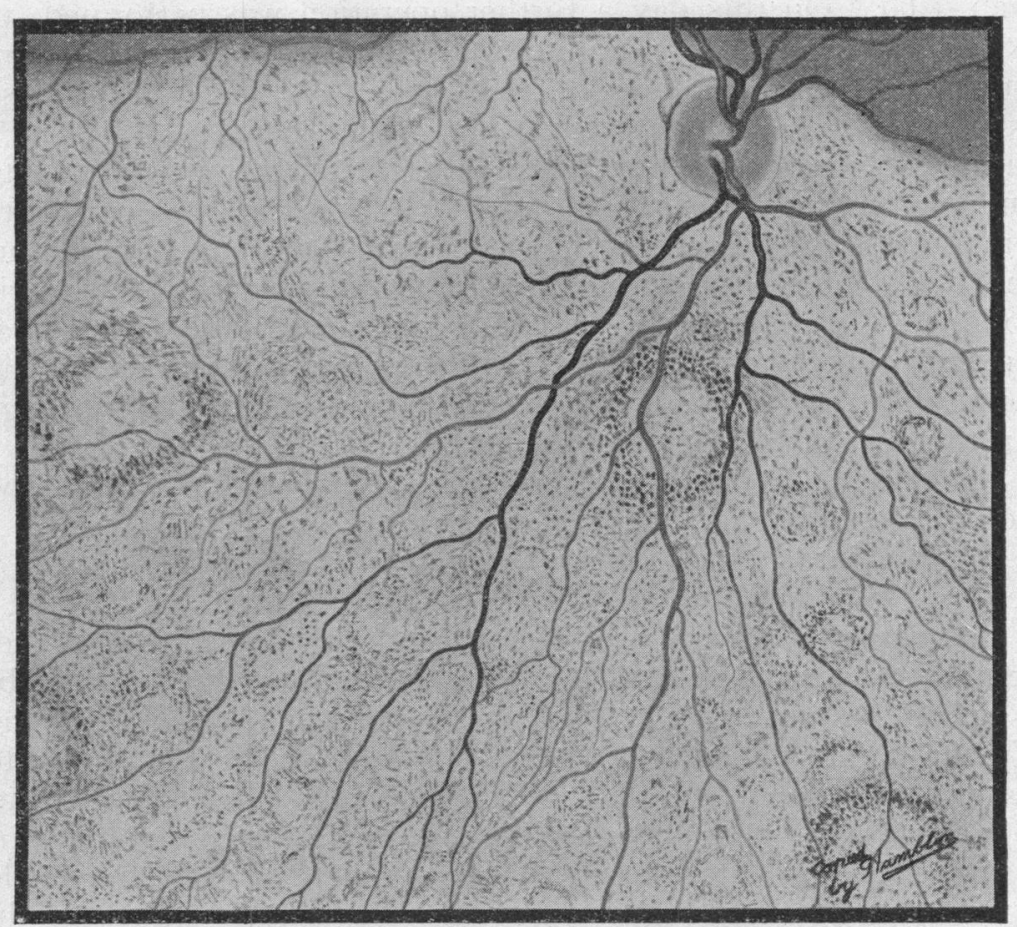

FIG. 4

Drawing of right fundus, post-operative. June 4, 1936. 
choroid. No trace of growth was to be seen. On September 14 the ocular condition was unchanged, but the patient complained of loss of weight and pain down the left arm, and had had two attacks of vomiting each lasting four or five days.

On re-examination on October 15 vision in the right eye was still 6/6 partly, but a fresh patch of new growth was seen adjacent to and continuous with the upper and outer margin of the disc and spreading outwards under the superior temporal vessels.

It was decided to repeat the previous insertion of radon seeds, approaching this time from above and from the outer side. On October 21 the area of growth which, on October 15, measured some five by three $\mathrm{mm}$., was again examined and was seen to have extended greatly. Downwards it had reached the macular area and was infiltrating the choroid previously pigmented; to the inner side it extended to about 2 o'clock of the disc and from thence upwards in a curve running temporally to the upper margin which appeared to be about two disc diameters from the periphery of visible retina; to the outer side the growth had practically reached this limit. At this time vision was probably not more than $3 / 60$. On this day a further operation was performed, the exposure being from the outer and upper side. The external and superior rectus muscles were identified and cut to assist exposure. Three radon seeds of an initial strength of 1.79 millicuries each were then stitched to the sclera $15 \mathrm{~mm}$. behind the limbus; one to the nasal side of the superior rectus; one to the temporal side and behind the insertion of the superior oblique; and one to the outer side and below the insertion of the superior oblique. The threads were maintained in a state of moderate tension by being brought forward through the upper lid and tied round thin rubber tubing, the second threads being again brought out through the conjunctival wound.

The cut rectus muscles were re-sutured and the conjunctival wound closed by an interrupted suture.

On October 27, after six days, the radon seeds were removed as before. Healing, though slow, was uneventful.

The patient's general condition was now very much worse, there being great loss of weight and incessant vomiting. On December 4 , vision had improved to $6 / 18$, and there was a characteristic lack of definition of the growth and the beginning of visible pigmented choroidal reaction. On December 18, vision was still 6/18 and the retina was quite flat, all trace of choroidal growth having disappeared. The whole fundus background was pale and mottled by the pigmentary reaction of the choroid and the disc was rather pale. Evidently the area affected by irradiation completely involved the macula.

On January 1, 1937, vision was $6 / 12$ (i) and the retina was 
entirely flat. The general condition of the patient was also temporarily improved and during the previous month she put on two pounds in weight.

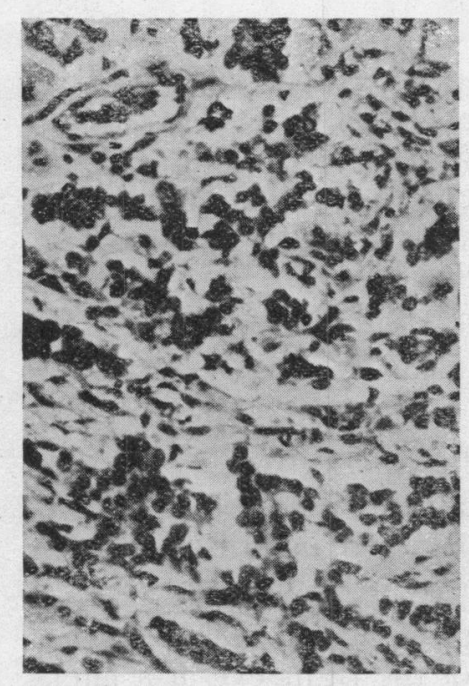

Fig. 5. Breast, $\times 230$.

(By courtesy of Dudley Road Hospital)

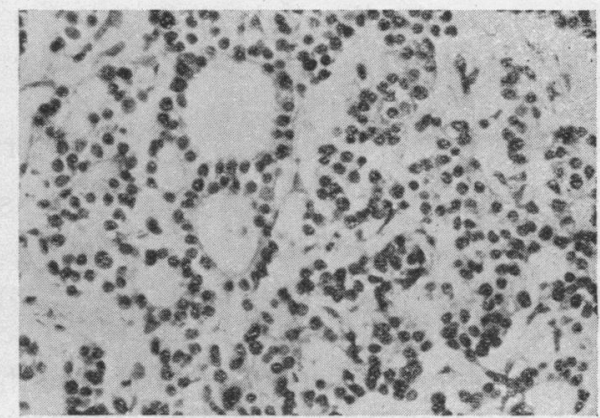

FIG. 6. Axillary Gland, $\times 230$.

(By courtesy of Dudley Road Hospital)

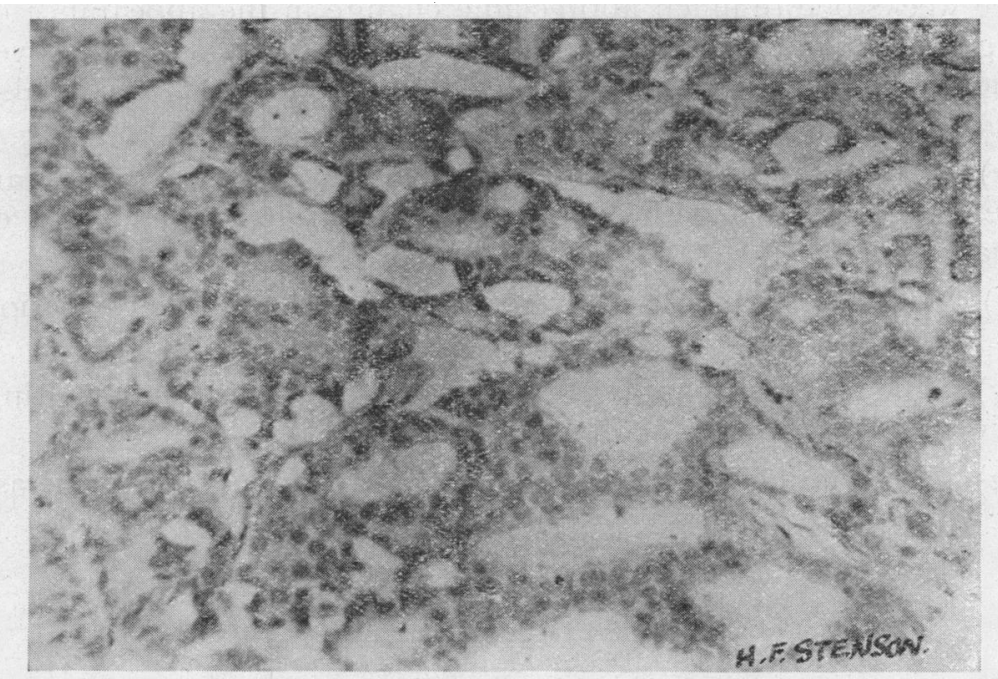

FIG. 7.

Metastatic carcinoma of choroid of left eye. 
By courtesy of the authorities of Dudley Road Hospital and of the pathologist there, I have been able to compare the sections of the tumour of the breast, with that in the axillary glands and the choroid. The original tumour (Fig. 5) was of a scirrhous type: while that in the axillary glands was not of very great activity (Fig. 6). The tumour in the eye (Fig. 7) on the contrary was more active as is shown by the rapid increase in size and the very favourable reaction to radon therapy.

In spite of evidence of further metastases the patient remains remarkably well in general condition and, although losing weight, is still active nearly five years after the original operation on the breast, and still retains good vision twelve months after the incidence of choroidal metastasis in the sole remaining eye.

\section{Summary}

The features of interest in this case are briefly these :-

(a) The occurrence of bilateral metastatic carcinoma of the choroid during a period of three months, two months elapsing between the incidence in the left eye and that in the right eye.

(b) The confirmation of the pathology in the case of the left eye and the exactly similar appearance of the right eye at a later date put the diagnosis in the second eye beyond doubt.

(c) The method of application of radon seeds to the sclera.

(d) The latent period, following the operation, of some two or three weeks before much appreciable change in the appearance of the growth took place; the progressive nature of this change over some two months; the widespread choroidal reaction which also was progressive for about the same period.

(e) The complete replacement of the retina upon the disappearance of the growth with full return of the visual field and of visual acuity.

$(f)$ Absence of any sign of recurrence in the eye over a period of seven months.

$(g)$ The successful application of radon a second time resulting again in disappearance of the tumour.

(h) The gradually increasing glandular character of the metastatic growths as compared with the primary breast tumour. 